\title{
O romancista e o vaqueiro: José de Alencar, leitor da poesia popular
}

\author{
Eduardo Vieira Martins \\ Universidade Estadual de Londrina
}

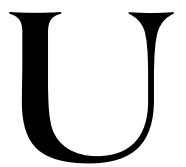

$m$ dos aspectos mais característicos do romantismo foi a valorização da cultura popular, que motivou escritores de diferentes países a compilar fábulas, contos e poemas transmitidos através dos tempos pela tradição oral. No Brasil, esse interesse deu lugar a uma importante pesquisa de José de Alencar sobre o cancioneiro popular cearense, romanticamente interpretado como uma espécie de repositório da nacionalidade: "É na trovas populares", diz ele, "que sente-se mais viva a ingênua alma de uma nação". ${ }^{1}$ Redigido na forma de quatro cartas enviadas a Joaquim Serra, esse estudo foi publicado no jornal O globo nos dias 7, 9, 10 e 17 de dezembro de 1874, e posteriormente editado nas Obras completas do romancista organizada por Afrânio Coutinho para a Editora Aguilar, onde aparece com o título de O nosso cancioneiro.

Nas cartas, José de Alencar examina as cantigas populares do Ceará, detendo-se sobre dois poemas dedicados ao que Câmara Cascudo chamou de "ciclo do gado". ${ }^{2}$ Com o auxílio de Capistrano de Abreu, na época um jovem de 21 anos de idade, Alencar obteve uma lição da cantiga d' $O$ Rabicho da Geralda, e confrontando-a com as quatro versões incompletas e truncadas que já possuía, lançou-se ao trabalho de reconstituí-la. É a versão restaurada dessa cantiga que, juntamente do Boi Espácio, absorve suas considerações sobre o cancioneiro cearense. Além do seu valor como

\footnotetext{
${ }^{1}$ ALENCAR, 1960. p. 961.

${ }^{2}$ CASCUDO, [s.d.].
} 
manifestação do interesse romântico pelas fontes folclóricas, essas cartas ganham um lugar especial no conjunto da produção crítica alencariana quando lembramos que foram escritas simultaneamente à redação de $O$ sertanejo (1875), romance em que traça o quadro da vida do vaqueiro no interior do Ceará. Já na primeira carta, depois de descrever a feição tomada pela pecuária do sertão, afirma: "Todas estas cenas dos costumes pastoris de minha terra natal, conto eu reproduzi-las com sua cor local, em um romance de que apenas estão escritos os primeiros capítulos". ${ }^{3}$ No ano seguinte, O sertanejo era publicado. Essa proximidade de datas e temas permite-nos afirmar que O nosso cancioneiro está para O sertanejo assim como as Cartas sobre "A confederação dos tamoios" está para O guarani: na posição de uma espécie de prefácio.

O processo histórico de introdução do gado no interior do Ceará e as condições de vida e de trabalho do vaqueiro são descritos por Alencar de forma bastante detalhada na primeira carta. Segundo ele, a pecuária do sertão era marcada por um elemento de perigo e aventura que a diferenciava da européia:

O vaqueiro cearense achou-se em face de um sertão imenso, e de grandes manadas de gado, esparsas pelo campo. Este sistema de criação, inteiramente diverso do europeu, obrigava o homem a uma luta constante. ${ }^{4}$

Esse aspecto de luta, decorrente de condições geográficas do território e de certas peculiaridades do rebanho, seria o principal diferenciador do trabalho do vaqueiro cearense, e deixaria marcas não apenas em seu caráter e costumes como também nas suas cantigas populares:

Na primitiva poesia do Ceará, predomina o gênero pastoril, como era razão entre populações principalmente dadas à indústria da criação, e derramadas por ubérrimas campinas coalhadas de toda espécie de gado.

Mas o estilo dessa poesia pastoril contrasta com o estilo clássico da musa grega ou romana, tanto quanto se destaca do estilo romântico dos zagais do Tirol e dos vaqueiros da Suíça.

Talvez não se encontre afinidades com estas rapsódias senão entre os árabes, povo com o qual, apesar da diferença de raça, o

\footnotetext{
${ }^{3}$ ALENCAR, 1960. p. 964.

${ }^{4}$ ALENCAR, 1960. p. 963. Grifo meu.
} 
cearense tem analogias topográficas, aptas a se lhe refletirem na índole e costumes.

A razão da singularidade provém de não revestirem as canções cearenses a forma de idílio. Não se inspiram no sentimento lírico, têm cunbo épico. São expansões ou episódios da eterna heróida do homem em luta com a natureza. ${ }^{5}$

Essa idéia, apresentada logo no início da primeira carta, constitui o eixo central que organiza O nosso cancioneiro, a sua tese. Significativamente, pode-se perceber nela a convivência de uma dupla matriz que, no meu entender, perpassa a reflexão teórica alencariana. Em primeiro lugar, há a matriz romântica, que compreende a literatura como produto do ambiente geográfico-cultural em que ela floresce. Como se sabe, essa proposição fecundou o pensamento dos nossos intelectuais no século xix e forneceulhes o instrumento de que necessitavam para afirmar a independência da literatura produzida no Brasil. Alencar recorreu a esse topos da crítica oitocentista inúmeras vezes para justificar a validade da sua própria produção literária, chegando mesmo a indagar, ironicamente, se "o povo que chupa o caju, a manga e a jabuticaba, pode falar uma língua com igual pronúncia e o mesmo espírito do povo que sorve o figo, a pêra, o damasco e a nêspera". ${ }^{6}$ Língua e literatura são, dessa perspectiva, instituições que se alimentam da seiva da terra, afeiçoando-se a ela. A fonte em que nossos escritores entraram em contato com essas idéias foi Mme de Staël, diretamente ou através de autores como Ferdinand Denis. É nas Cenas da natureza sob os trópicos, aliás, que encontramos uma aproximação entre os pastores da América e da Arábia bastante semelhante à estabelecida por Alencar:

Embora eles tenham praticamente as mesmas ocupações, sentese que os pastores da Arábia, e os das planícies incultas do Novo Mundo, devem encantar as suas horas de folga por meio de cânticos que diferem dos europeus, tanto quanto as solidões em que eles vivem estão longe de assemelhar-se às da Grécia ou da Itália. ${ }^{7}$

A segunda matriz perceptível no comentário de Alencar anteriormente citado é fornecida pela retórica. Tradicionalmente, a historiografia literária

\footnotetext{
5 ALENCAR, 1960. p. 962. Grifo meu.

${ }^{6}$ ALENCAR, [s.d.]. p. 13.

7 DENIS, apud ROUANET, 1991. p. 230.
} 
aponta o abandono das preceptivas retórico-poéticas que orientaram a produção do discurso até fins do século xviII como uma das principais linhas de demarcação da estética romântica. Ainda que correta, essa proposição não deve ser levada tão longe a ponto de encobrir a profunda ligação do romantismo com as fontes clássicas. Segundo Roberto Acízelo de Souza,

no Brasil, a crítica literária oitocentista segue a tendência mundial, tendo no historicismo o seu modelo orientador. No entanto, é preciso reconhecer [...] que, convivendo com o paradigma historicista hegemônico, a produção crítica orientou-se também por uma vertente de procedência clássica, que sobrevive aos triunfos do romantismo, prolongando a vigência de duas disciplinas antigas do discurso, a retórica e a poética. ${ }^{8}$

Essa permanência da retórica se manifesta na produção de manuais de eloqüência - divulgados, principalmente, através das escolas - e na continuidade do debate de temas literários colocados pela estética clássica. Em A divisão das águas, Hélio Lopes observa que "as discussões ao redor das preceptivas tradicionais interessam os românticos profundamente", posto que eles "nunca abandonaram, por completo, o lastro greco-latino, quando o receberam em sua formação. O classicismo fecunda o Romantismo como uma fonte subterrânea".?

No caso de José de Alencar, a presença de conceitos oriundos da retórica é facilmente detectável nas suas reflexões sobre a literatura. ${ }^{10} \mathrm{No}$ fragmento de $O$ nosso cancioneiro que estamos analisando, ela se manifesta na preocupação com a determinação do gênero no qual as cantigas cearenses se enquadram. Vale notar que, mesmo depois do grito de liberdade de Victor Hugo contra a rígida classificação dos gêneros e da flexibilização das suas fronteiras operada pelo romantismo, esse tema é freqüentemente debatido por Alencar. Para ele, as cantigas populares cearenses se enquadram no gênero pastoril; contudo, ao contrário do que ocorreria na Europa, essa forma poética não tomaria aqui os tons amenos do idílio, e sim as cores mais fortes da epopéia, que lhe seriam infundidas

\footnotetext{
${ }^{8}$ SOUZA, 1999. p. 26.

${ }^{9}$ LOPES, 1978. p. 176 e 204.

${ }^{10}$ As idéias apresentadas neste artigo fazem parte de um projeto de doutorado que pretende analisar os textos críticos de Alencar, confrontando-os com as retóricas que circulavam no Brasil no século xIx.
} 
pelo caráter de luta assumido pela pecuária do sertão. Note-se, então, que as duas matrizes de pensamento - a romântica e a retórica - não permanecem impermeáveis uma à outra, antes se mesclam e se fundem no esforço de compreender o fenômeno literário analisado. Assim, para sustentar a afirmação de que as cantigas cearenses possuem caráter épico, o missivista descreve a atividade do vaqueiro procurando ressaltar o "cunho cinegético" de que ela se reveste no sertão, para daí concluir que "as nossas rudes bucólicas cearenses [não podiam] se impregnar da mesma doçura e amenidade das que outrora cantaram Teócrito e Virgílio, e que ainda hoje se reproduzem nos colmos dos pegureiros do Velho Mundo". ${ }^{11}$

O problema da classificação dessas cantigas é retomado por Alencar em outras cartas. A propósito do Boi Espácio, comenta:

Não sei na classificação literária que nome se possa dar com propriedade a essa e a outras composições populares de nosso país. Pelas investigações de Garret no seu Romanceiro, parece que elas de um lado frisam com a xácara, por serem dialogadas entre os interlocutores, ou narradas por um deles; do outro lado se aproximam do romance pelo tom épico ou narrativo sem ornatos líricos. ${ }^{12}$

Posteriormente, Alencar irá recusar essas classificações, considerando que xácara e romance são "nomes cultos" e, portanto, inadequados às "inspirações rústicas e aos improvisos incorretos de nossos sertanejos". ${ }^{13}$ Sua recusa, entretanto, não suprime a importância de toda essa reflexão pautada pela teoria dos gêneros e pela análise da ornamentação mais conveniente a cada um deles, como se percebe claramente na passagem citada.

Também ao analisar o Rabicho da Geralda Alencar procura determinar o seu gênero. Como o poema é narrado pelo próprio boi, a classificação se torna mais fácil: para ele, a cantiga "tem a forma da prosopopéia". ${ }^{14}$ Ao enquadrá-lo nessa forma, o romancista segue a tradição retórica, como se pode perceber pela leitura, por exemplo, de Francisco Freire de Carvalho, autor das Lições elementares de eloqüência nacional, um dos principais manuais do período:

\footnotetext{
${ }^{11}$ ALENCAR, 1960. p. 964-965.

12 ALENCAR, 1960. p. 970.

${ }^{13}$ ALENCAR, 1960. p. 970.

${ }^{14}$ ALENCAR, 1960. p. 978.
} 
Prosopopéia ou Personificação é uma figura com que o orador introduz ficticiamente a falar pessoas verdadeiras; ou mais propriamente, com que atribui sentimento, vida e racionalidade a seres, a quem estas qualidades não competem. ${ }^{15}$

No caso do Rabicho da Geralda, mais importante do que a determinação do seu gênero, são as considerações desenvolvidas a propósito do caráter nela assumido pelo boi. Segundo Alencar, a principal característica dos poemas que cantavam as façanhas do gado era a "apoteose do animal", o fato de neles o herói ser o boi, e não o homem. ${ }^{16}$ O que lhe parece fundamental é que não haveria nessa abordagem nenhuma tendência de humanizar o boi:

Nem vestígios se encontram de alegoria nessas rapsódias; o boi figura por si, tem uma individualidade própria. Daí o cunho mitológico desses heróis sertanejos.

$\mathrm{Na}$ infância dos povos, certas individualidades mais pujantes absorvem em si a tradição de fatos praticados por indivíduos cujo nome se perde; e tornam-se por esse modo símbolo de uma idéia ou de uma época.

Com o incremento da civilização, que nivela os homens, debilita-se aquela tendência; e o mitologismo só aparece naquelas latitudes sociais onde ainda não dissiparam-se de todo a primitiva rudeza e ingenuidade do povo.

Estou convencido de que os heróis das lendas sertanejas são mitos, e resumem o entusiasmo do vaqueiro pela raça generosa, companheira inseparável de suas fadigas, e próvida mãe que o alimenta e veste.

O caráter poético das nossas rapsódias pastoris não é comum a outros países. ${ }^{17}$

Na visão alencariana, o mito é o ser que, ao concentrar em si a tradição de feitos grandiosos praticados por indivíduos cujos nomes foram esquecidos, alça-se a uma categoria simbólica, tornando-se o representante das virtudes mais caras a uma comunidade. Logo, o conceito alencariano de mito pressupõe um processo cumulativo de qualidades para o qual concorrem, sem dúvida, a tradição oral e a literatura. Conferir estatura mítica a

\footnotetext{
${ }^{15}$ CARVALHO, 1880. p. 154.

${ }^{16}$ ALENCAR, 1960. p. 977.

${ }^{17}$ ALENCAR, 1960. p. 978. Grifo meu.
} 
personagens e cenários equivale a transformá-los nessas "individualidades mais pujantes" que simbolizam uma idéia ou uma época. Na leitura que faz do cancioneiro popular, Alencar identifica dois ornatos retóricos empregados pelos vates do sertão para mitificar seus heróis: a hipérbole e a amplificação.

Hugh Blair, autor das Lectures on rhetoric and belles lettres, manual amplamente divulgado no Brasil do século xix através de traduções francesas, é bastante sucinto ao definir a figura que ele chama de "hyperbole, or exageration": "It consists in magnifying an object beyond its natural bounds" ${ }^{18}$ Já o Pe. Lopes Gama, nas Lições elementares de eloqüencia nacional, livro muito provavelmente conhecido por Alencar, ${ }^{19}$ desenvolve mais a análise dessa figura:

Quando estamos vivamente penetrados duma idéia, e os termos comuns nos parecem apoucados para levantar o espírito até a expressão correspondente, nos servimos de palavras, que literalmente tomadas passam além da verdade, e representam mais, ou menos para significar algum excesso, assim no grande como no pequeno. O ouvinte rebaixa da expressão hiperbólica o que é mister rebaixar, formando uma imagem mais conforme à nossa, do que a que poderíamos excitarlhe com as palavras próprias. ${ }^{20}$

Alencar aponta o uso da hipérbole no poema do Boi Espácio, cantiga na qual um vaqueiro, "depois de agarrar o [boi] foragido e matálo, conta saudoso as proezas do brioso animal":

${ }^{18}$ BLAIR, 1829. p. 169.

${ }^{19}$ Apesar de Alencar não o citar diretamente, dois indícios tornam provável que ele o conhecesse. Em primeiro lugar, ao final do livro uma "Lista dos Senhores Subscritores" traz o nome de José Martiniano de Alencar. Como em 1846, data da publicação, o futuro romancista contava apenas 17 anos, tratase, evidentemente, do seu pai. Contudo, deve-se admitir que a presença do livro na biblioteca paterna atraísse a atenção de um rapaz interessado nas discussões literárias. O segundo indício é o fato de Lopes Gama dirigir o Curso Jurídico de Olinda quando Alencar o freqüentou. Tendo assumido a direção em 1847, um ano depois da publicação do tratado, é muito provável que ele circulasse entre professores e alunos, podendo até mesmo ter sido adotado como livro de estudo.

${ }^{20}$ GAMA, 1846. tomo I, p. 156-157. 
Segue-se a comemoração das façanhas do touro valente; e termina o poemeto com o espólio do animal, em que a hipérbole, ultrapassando as raias do verossímil, atesta a extrema admiração que devia ter inspirado o herói.

Para fazer idéia da exageração aqui vai a amostra:

"Um chifre do boi Espácio,

Dele fez-se uma canoa

Para se passar a gente

Que viesse de Lisboa" ${ }^{21}$

A compreensão que Alencar tem desse ornato coincide com a dos retóricos anteriormente citados. Da mesma maneira que Lopes Gama, a hipérbole é percebida aqui como um recurso capaz de fixar a paixão despertada no orador pelo objeto do seu canto e transmiti-la ao destinatário do discurso. No Boi Espácio, é a "extrema admiração" que o vate sertanejo sente pelo boi que o arrasta para o uso da hipérbole, ornato que, por sua vez, deverá mover o ouvinte em direção ao mesmo pathos.

Quanto à amplificação, Hugh Blair considera que ela não é propriamente uma figura mas uma forma de organizar as figuras de um discurso de maneira a produzir um aumento ou uma diminuição da(s) qualidade(s) que o orador deseja ressaltar ou atenuar. Haveria diferentes maneiras de se obter esse efeito, sendo que, para nossos objetivos, a mais interessante é a que se faz por comparação. ${ }^{22}$ Francisco Freire de Carvalho, por sua vez, classifica a amplificação entre os conceitos fortes e a define como "aquele [conceito] que serve para engrandecer ou apoucar os objetos". Haveria, segundo ele, duas maneiras de amplificar um objeto: a absoluta, na qual ele é considerado "em si mesmo", e a relativa, que "sai fora do objeto, e comparando-o com outro de uma ordem inferior, igual ou superior, consegue avultá-lo muito mais do que antes se afigurava”. ${ }^{23}$ A descrição que Lopes Gama faz da amplificação simplesmente repete, quase que com as mesmas palavras, as considerações desenvolvidas por Freire de Carvalho. ${ }^{24}$

\footnotetext{
${ }^{21}$ ALENCAR, 1960. p. 971.

22 BLAIR, 1829. p. 191.

${ }^{23}$ CARVALHO, 1880. p. 105-106.

${ }^{24}$ GAMA, 1846. tomo I, p. 113-114.
} 
Ao contrário do que vimos com a hipérbole, Alencar não utiliza o termo "amplificação" em O nosso cancioneiro; contudo, mesmo sem nomeá-la, aponta sua utilização no Rabicho da Geralda. Prosseguindo a análise da feição assumida pelo boi nessa cantiga, afirma que, diferentemente do que ocorre na poesia de outros países, na qual o animal surge como "sócio" ou mesmo "servo" do homem, no cancioneiro cearense o boi é o herói celebrado na cantiga:

Aí está o toque de magnanimidade dos rústicos vates do sertão. Homero engrandece os guerreiros troianos para realçar o valor dos gregos. Os nossos rapsodos, imitando, sem o saberem, ao criador da epopéia, exaltam o homem para glorificar o animal. ${ }^{25}$

O dispositivo consiste em contrapor o objeto que se pretende amplificar (os guerreiros gregos, no caso de Homero, ou o boi, no dos sertanejos) a outro objeto que, em si, já apresenta em alto grau a qualidade que se pretende exaltar (a bravura dos troianos, no primeiro caso, ou dos vaqueiros, no segundo); a seguir, o poeta demonstra que o objeto do seu canto supera esse comparante em grandeza, amplificando, assim, o seu valor.

\section{2}

Alguns aspectos temáticos e formais identificados por Alencar em O nosso cancioneiro são retomados em O sertanejo. No plano temático, cumpre observar que o trabalho do vaqueiro é descrito de forma bastante semelhante tanto nas cartas quanto no romance, sendo que em ambos se ressalta o elemento de perigo e de aventura que caracterizaria a pecuária sertaneja. A introdução do gado nesse território também é analisada da mesma maneira nos dois textos. Em O nosso cancioneiro, Alencar defende a tese de que apesar de não ser nativo do sertão, o gado teria encontrado aí as condições necessárias para se fortalecer e reproduzir:

Desde os princípios da povoação, que as diversas espécies de animais domésticos introduzidos pelos colonizadores se propagaram com intensidade; a Providência nos seus impenetráveis desígnios havia preparado a América para a regeneração das raças exaustas do Velho Mundo.

${ }^{25}$ ALENCAR, 1960. p. 978. 
As imensas campinas, que se dilatam desde o S. Francisco até o Parnaíba, por que a natureza as proveria de tamanha abundância de plantas forrageiras, quando a sua fauna indígena não contava mais que um tipo da ordem dos grandes ruminantes? ${ }^{26}$

A partir de uma perspectiva teleológica da história, busca-se explicar a adaptação de espécies adventícias como parte dos desígnios da providência divina. De forma mais desenvolvida, a mesma idéia já havia sido expressa em o gaúcho, no qual o pampa surge como uma espécie de local privilegiado, reservado por Deus para receber os animais trazidos da Europa e fornecer-lhes as condições ideais para que se desenvolvessem:

Não recebeu a América, do Criador, as três raças de animais amigos e companheiros do homem, o cavalo, o boi e o carneiro. Esse fato, que à primeira vista parece uma anomalia da natureza, revela ao contrário um desígnio providencial. Regenerar, é a missão da América nos destinos da humanidade. Foi para esse fim, que Deus estendeu de um pólo ao outro este vasto continente, rico de todos os climas, fértil em todos os produtos, e o escondeu por tantos séculos sob uma prega de seu manto inconsútil. ${ }^{27}$

Alencar trabalha nessa passagem com um dos temas centrais de sua obra, o da superioridade da natureza americana sobre a européia. A ausência das "raças nobres" na América é atribuída a um projeto divino que reservaria ao continente a missão de regenerar "todos os produtos úteis do velho continente", ${ }^{28}$ fossem eles homens, animais, hábitos ou instituições. Dessa maneira, o que poderia parecer deficiência é interpretado como riqueza e superioridade.

O gado levado para o sertão também teria sido beneficiado pelos influxos revitalizadores da natureza americana. Além do novo vigor recebido das "ubérrimas campinas", ${ }^{29}$ parte do rebanho teria fugido das fazendas, retornando a uma condição quase selvagem:

Ou logo nos primeiros ensaios de colonização, ou mais tarde com a devastação das granjas e engenhos durante a invasão holandesa, o gado

\footnotetext{
${ }^{26}$ ALENCAR, 1960. p. 962-963.

${ }^{27}$ ALENCAR, 1977. p. 85.

${ }^{28}$ ALENCAR, 1977. p. 85.

${ }^{29}$ ALENCAR, 1960. p. 962.
} 
amontou-se. Internando-se pelo sertão, aí voltou ao estado selvagem. Ainda hoje encontra-se pelos sítios escuros algum, a que na província chamam barbatão". ${ }^{30}$

O mesmo tema ressurge, de forma bastante semelhante, em O sertanejo:

O gado de várias espécies, que os primeiros povoadores tinham introduzido na Capitania do Ceará, se propagara de um modo prodigioso por todo o sertão, coberto de ricas pastagens.

Sucedera o mesmo que nos pampas do Sul; as raças se tornaram silvestres, e manadas de gado amontado, que ainda hoje na província chama-se barbatão, vagavam pelos campos e enchiam a mata. ${ }^{31}$

O barbatão é o gado selvagem, "nascido no mato ou fugido das fazendas". ${ }^{32}$ Em O nosso cancioneiro, Alencar diz desconhecer a origem da palavra, que supõe ser oriunda do Ceará ou da ribeira do São Francisco. Especulando sobre sua possível etimologia, afirma:

Pode ser que barbatão não passe do aumentativo de barbato para significar o longo e denso pêlo do gado criado no mato.

Não seria desarrazoado também derivá-lo de brabo, variante rústica de bravo. ${ }^{33}$

Essa primeira hipótese de etimologia é retomada em O sertanejo, quando, ao descrever uma manada, o narrador observa que o gado, "no comprido pêlo e no aspecto arisco mostrava ser barbatão". ${ }^{34}$ Outro termo usado para designar o boi selvagem é "mocambeiro", gado que fugiu das fazendas para os mocambos.

Em O sertanejo, os campos de Quixeramobim são descritos como contendo grande quantidade de bois selvagens. "Naquele tempo é certo que o gado barbatão multiplicava-se com prodigiosa rapidez; e os vastos campos incultos, bem como as florestas ainda virgens, ofereciam às manadas

30 ALENCAR, 1960. p. 963.

31 ALENCAR, 1965. p. 542.

${ }^{32}$ ALENCAR, 1960. p. 964. No dicionário de Antonio de Moraes Silva, o barbatão é definido como "o gado bovino que não foi marcado na fazenda, e que, vivendo no mato, se torna bravio". Ver SILVA, 1813.

33 ALENCAR, 1960. p. 963.

${ }^{34}$ ALENCAR, 1965. p. 630. 
selvagens refúgios impenetráveis". ${ }^{35}$ A caminho do local onde se realizaria a monteria, os viajantes cruzam campos e várzeas "coalhados" de gado. "É boi como terra!", exclama um personagem ao avistar os enormes rebanhos. ${ }^{36}$ Durante a monteria, um boi surubim avança sobre D. Flor. Trata-se de "um animal corpulento, de marca prodigiosa, como raros exemplares se encontram no sertão, hoje que as nossas raças domésticas estão decaídas daquele vigor primitivo que tomaram ao influxo e contato do novo mundo".37

A força e energia do barbatão viria do seu contato direto com o mato. Longe da influência domesticadora do homem, o gado selvagem viveria em estreita relação com o sertão inculto, livre para absorver os influxos da natureza americana. São esses animais indômitos, e não os domesticados, que chamam a atenção de José de Alencar. Dentre os diversos bois descritos em O sertanejo, nenhum se destaca tanto quanto o Dourado, um touro que havia anos vagava pelos campos, sem que vaqueiro algum conseguisse aprisioná-lo: "Era um boi alto e esguio. [...] Em vez das largas patas e grossos artelhos dos animais de trabalho, ele tinha as pernas delgadas e o jarrete nervoso dos grandes corredores". ${ }^{38}$

A caracterização do Dourado é construída a partir de elementos que ressaltam o seu caráter sublime, conceito que Hugh Blair e Francisco Freire de Carvalho, retomando as idéias apresentadas por Edmund Burke em $A$ philosophical enquiry into the origin of our ideas of sublime and beautiful (1757), compreendem como uma espécie de grandiosidade das coisas da natureza. "Nothing", diz Blair, "is more sublime than mighty power and strength. [...] From lions and others animals of strength, are drawn sublime comparisons in poets". ${ }^{39}$ Como num quadro de Géricault, Alencar retrata um animal em perfeita harmonia com o cenário bravio onde se encontra. As qualidades do touro - a altivez e majestade selvagem, o nervosismo e energia - devem-se ao fato de ele não ter conhecido o "despotismo do homem" e ter vivido sempre "à lei da natureza". O que o diferencia do resto do gado bravio e faz dele o "rei dos pastos de Quixeramobim" é o

\footnotetext{
${ }^{35}$ ALENCAR, 1965. p. 637.

36 ALENCAR, 1965. p. 630.

${ }^{37}$ ALENCAR, 1965. p. 639.

${ }^{38}$ ALENCAR, 1965. p. 634

39 BLAIR, 1829. p. 33.
} 
fato de permanecer ainda mais livre e isolado que os outros. ${ }^{40} \mathrm{O}$ tratamento que lhe é dado pelo ficcionista pode parecer estranho para o leitor de hoje, mas se esclarece quando inserido no contexto das considerações desenvolvidas por Alencar a propósito das cantigas populares cearenses. Como os vates incultos de sua terra natal, o romancista exalta o Dourado, elevando-o a uma estatura mítica e convertendo-o num dos heróis de sua epopéia sertaneja.

No tocante à incorporação em O sertanejo de recursos formais identificados por Alencar nas cantigas populares cearenses, percebe-se claramente no romance o uso da hipérbole e da amplificação. A primeira manifesta-se na exaltação das qualidades de alguns personagens, sejam eles homens, como o vaqueiro Arnaldo, Dona Flor e o capitão-mor Gonçalo Pires Campelo, ou animais, como o Dourado ou o Corisco, cavalo de Arnaldo. Quanto aos animais, a exageração chega ao ponto de se afirmar que eles faziam cálculos táticos e estratégias para atingir suas finalidades, atribuindo-lhes, assim, inteligência. Esse uso da hipérbole sempre foi atacado pela crítica, que, desde Franklin Távora e Araripe Jr., censura o excesso de exageração empregado pelo romancista, imputando-o de falsear a realidade. Da perspectiva alencariana, entretanto, a hipérbole, mesmo tocando o inverossímil, seria apenas um recurso estilístico válido para mitificar seus heróis.

A amplificação relativa, apontada por Alencar no Rabicho da Geralda, também é utilizada em diversas passagens de O sertanejo. Para conferir estatura mítica ao Dourado, por exemplo, o narrador o contrapõe aos bois celebrados nas cantigas populares, como o Rabicho da Geralda, exaltado no poema homônimo. Discutindo sobre qual deles seria superior, o capitão-mor Campelo afirma:

- O Rabicho da Geralda, Sr. Daniel Ferro, foi sem dúvida um corredor de fama. Nós ainda conhecemos o José Lopes, vaqueiro da viúva, que nos contou as proezas de seu boi. Mas nosso parecer é que não chegava ao Dourado. ${ }^{41}$

Ao aproximar seu herói do grande boi celebrado na cantiga, o narrador amplifica suas qualidades, alçando-o a um patamar mais elevado do que poderia fazer por mera enumeração de seus feitos.

\footnotetext{
${ }^{40}$ ALENCAR, 1965. p. 634.

${ }^{41}$ ALENCAR, 1965. p. 632.
} 
Esse tipo de comparação, sempre afirmando a superioridade do Dourado, é uma tentativa de projetar sobre ele a tradição de feitos atribuídos a outros bois, fazendo dele o sucessor e o maior desses mitos. A idéia simbolizada pelo touro indômito seria a da força e energia da terra sertaneja. Ao contrário do Rabicho da Geralda, entretanto, que vence os mais famosos vaqueiros e só é aprisionado durante (e por causa de) uma forte seca, o Dourado não tem a mesma sorte. Perseguido por Arnaldo numa corrida fabulosa, acaba sendo pego. Diferentemente dos "rústicos vates do sertão", que "exaltam o homem para glorificar o animal", ${ }^{42}$ para Alencar interessa a apoteose do sertanejo; e é Arnaldo, mais que qualquer outro ser, o grande mito desse romance, é ele que melhor sintetiza e representa as qualidades do sertão, sendo capaz de vencer até mesmo o "rei dos pastos de Quixeramobim".

A amplificação relativa também é utilizada na descrição dos vaqueiros, constantemente comparados a outros cavaleiros consagrados pela tradição. Assim, discutindo com Daniel Ferro, Campelo compara Louredo, pai de Arnaldo, a Inácio Gomes, celebrado nos versos do Rabicho da Geralda (além da comparação, note-se ainda a semelhança do nome do personagem da cantiga com o de Inácio Góis, vaqueiro da Oiticica; na cantiga também há um personagem chamado Góis):

- Veja o Senhor Capitão-Mor que o 'Rabicho' zombou dos melhores cantigueiros de todos estes sertões, até do Inácio Gomes que ainda hoje tem nome na ribeira do São Francisco.

- Não era nada à vista do Louredo, nosso vaqueiro; pode acreditar, que é a verdade. ${ }^{43}$

Quando Arnaldo, perseguindo o Dourado pela mata, salta da sela para vencer um obstáculo que ia derrubá-lo, Daniel Ferro cita novamente o Rabicho da Geralda, "que celebra um passo análogo": "Tinha adiante um pau caído/ Na descida de um riacho;/ O cabra saltou por cima,/ O ruço pulou por baixo". Arnaldo, ao ouvir os verso da cantiga, "responde com o palavreado do Inácio Gomes, quando corria atrás do Rabicho": "Corra, corra, camarada,/ Puxe bem pela memória;/ Quando eu vim de minha terra,/ Não foi pra contar histórias". ${ }^{4}{ }^{4}$

\footnotetext{
42 ALENCAR, 1960. p. 978.

${ }^{43}$ ALENCAR, 1965. p. 632.

${ }^{44}$ ALENCAR, 1965. p. 644.
} 
As comparações amplificantes não se restringem aos vaqueiros das cantigas, elas também tomam por modelo cavaleiros de outros tempos e lugares:

Essa corrida cega pelo mato fechado é das façanhas do sertanejo a mais admirável. Nem a destreza dos árabes e dos citas, os mais famosos cavaleiros do Velho Mundo; nem a ligeireza dos guaicurus e dos gaúchos, seus discípulos, são para comparar-se com a prodigiosa agilidade do vaqueiro cearense. ${ }^{45}$

Os cavaleiros medievais fornecem ampla matéria para comparações. Na monteria, quando Arnaldo finalmente alcança o Dourado e o pega pela cauda, ele não o derruba, apesar de achar-se em condições de o fazer. Segundo o narrador, o vaqueiro o tratava "com a gentileza que os cavalheiros usavam outrora no combate; e derrubada era uma afronta que não infligiria a um corredor de fama como aquele". ${ }^{46}$ Em nenhum momento a aproximação do universo sertanejo ao da cavalaria é tão completa quanto no paralelo estabelecido por Daniel Ferro entre os feitos dos vaqueiros e os dos cavaleiros medievais:

- E que pensa, Fragoso, que nossos vaqueiros não seriam homens para pedir meças em jogos de destreza aos mais esforçados paladinos de outras eras? Por mim tenho que nunca Roldão, Lançarote ou algum outro dos doze pares de França, estacou na ponta de sua lança um cavalheiro à disparada com tanta bizarria, como tenho visto topar um touro bravo na ponta da aguilhada. ${ }^{47}$

Da mesma maneira que na descrição do Dourado, a aproximação de Arnaldo aos vaqueiros das cantigas populares ou aos cavaleiros medievais surge como tentativa de projetar sobre ele os feitos praticados por outros indivíduos, convertendo-o em símbolo da grandeza dessa comunidade, o que, da perspectiva alencariana, era um recurso para dotá-lo de estatura mítica.

\footnotetext{
45 ALENCAR, 1965. p. 645.

${ }^{46}$ ALENCAR, 1965. p. 647.

${ }^{47}$ ALENCAR, 1965. p. 595.
} 


\section{3}

O estudo aprofundado que José de Alencar faz da pecuária sertaneja em O nosso cancioneiro revela a atenção que despendia às suas fontes documentais e coloca em xeque sua imagem como escritor puramente intuitivo e governado pela imaginação. A escolha do Ceará para palco de O sertanejo pode ter sido influenciada pelas duras críticas feitas por Franklin Távora nas páginas do jornal Questões do dia, acusando-o de desconhecer as regiões retratadas em seus romances e, em conseqüência, de incorrer em toda sorte de erros. O estudo das condições de vida do vaqueiro cearense forneceu-lhe uma base sólida para alicerçar sua narrativa, evitando ataques como esse.

O uso em O sertanejo de elementos identificados no Boi Espácio e no Rabicho da Geralda é sinal inequívoco do desejo alencariano de vincular o romance à tradição da poesia popular, compreendida como repositório da "ingênua alma de uma nação". Uma vez que Alencar classificava essas canções no gênero épico, a incorporação no romance de temas e recursos formais oriundos delas parece mais um passo na pesquisa de uma forma épica genuinamente nacional, iniciada no plano teórico em 1856, com a discussão sobre A confederação dos tamoios, e da qual Oguarani (1857) representa a primeira tentativa de concretização. Se considerarmos que as cartas que compõem O nosso cancioneiro representam reflexões tardias do escritor e que O sertanejo foi seu último romance publicado em vida, veremos que Alencar foi extremamente coerente ao longo de sua carreira de romancista e perseguiu com estudo e afinco a realização de suas idéias. 


\section{Referências Bibliográficas}

ALENCAR, José de. Benção Paterna. In: Sonhos d'ouro. São Paulo: Melhoramentos, [s.d.].

ALENCAR, José de.O gaúcho e O tronco do ipê. Rio de Janeiro: José Olympio, 1977.

ALENCAR, José de. O nosso cancioneiro. In: Obra completa. Rio de Janeiro: Aguilar, 1960. v. IV.

ALENCAR, José de.O sertanejo. In: Ficção completa e outros escritos. Rio de Janeiro: Aguilar, 1965. v. III.

BLAIR, Hugh. Lectures on rhetoric and belles lettres. Philadelphia: James Kay, Jun. and Brother, 1829.

CARVALHO, Francisco Freire de. Lições elementares de eloqüência nacional. Lisboa: Rolland \& Semiond, 1880.

CASCUDO, Câmara. Dicionário do folclore brasileiro. Rio de Janeiro: Edições de Ouro, [s.d.].

GAMA, Miguel do Sacramento Lopes. Lições de eloqüência nacional. Rio de Janeiro: Tipografia Imparcial de F. de Paula Brito, 1846.

LOPES, Hélio. A divisão das águas. São Paulo: Conselho Estadual de Artes e Ciências Humanas, 1978.

ROUANET, Maria Helena. Eternamente em berço esplêndido. São Paulo: Siciliano, 1991.

SILVA, Antonio de Moraes. Dicionário da lingua portuguesa. Lisboa: Tip. Lacérdina, 1813.

SOUZA, Roberto Acízelo de. O império da eloqüência. Rio de Janeiro: EdUERJ/ EdUFF, 1999 . 


\section{Resumo}

Este artigo pretende discutir a análise das cantigas populares desenvolvida por José de Alencar em O nosso cancioneiro (1874). Num primeiro momento, procura-se demonstrar que o autor, lançando mão de conceitos oriundos da retórica, classifica as canções do Boi Espácio e do Rabicho da Geralda no gênero épico e identifica dois ornatos utilizados para dotar o boi de estatura mítica: a hipérbole e a amplificação. Num segundo momento, verifica-se como Alencar incorporou temas e procedimentos estilísticos identificados nessas canções em O sertanejo (1875), romance redigido simultaneamente ao estudo sobre o cancioneiro popular cearense.

\section{Résumé}

Ce travail a comme objectif discuter l'analyse des chansons populaires faite par José de Alencar dans O nosso cancioneiro (1874). Premièrement, nous essayons de montrer que l'auteur, en utilisant des concepts de la rhétorique, classifie les chansons Boi Espácio et Rabicho da Geralda dans le genre épique. Il identifie deux ornements utilisés pour convertir le bœuf dans un mythe: l'hyperbole et l'amplification. Ensuite, nous vérifions comment Alencar a utilisé ces deux procédés stylistiques dans O sertanejo (1875), romam écrit en même temps que O nosso cancioneiro. 